\title{
High-speed railway pantograph and catenary dynamic simulation system modelling and verification
}

\author{
J. F. Guan, J. Q. Wu \& Y. Zhong \\ School of Electrical Engineering, Southwest Jiaotong University, China
}

\begin{abstract}
The dynamic simulation system of a pantograph and a catenary has been built by using the finite element method, in which the pantograph is equivalent to a threemass-damper-stiffness system and the catenary contains only cable and beam elements. Considering droppers as nonlinear elements only stressed by tension, a sliding contact model of the pantograph and catenary is coupled by penalty function. Nodal displacement and element stress can be obtained by direct time integration. Finally, the contact force and deformation of the pantograph and catenary is achieved by entering the parameters in standards and from the actual Wuhan-Guangzhou high-speed railway into this simulation system. When comparing the standards, commercial software and measured data, the credibility of the simulation system can be verified. This simulation system provides an efficient way for the design and structure optimization of a pantograph and catenary system.
\end{abstract}

Keywords: pantograph, catenary, simulation, verification.

\section{Introduction}

The pantograph and catenary system is used to supply power to trains by sliding, as shown in fig. 1. Catenary is set up along railway lines and pantographs attached on roof of trains. And power goes from the catenary to pantographs from their contact points, whose quality decides the efficiency of power transmission. In high-speed movement, working condition of pantographs are seriously affected by air and catenary. Therefore it is necessary to conduct research into the dynamics of the pantograph and catenary system. Nowadays, there are two efficient ways to 
obtain dynamics of the system: by measurement and by simulation. However, parameters got by measuring reflect the performance of existing lines and only simulation results can be used for future optimization.

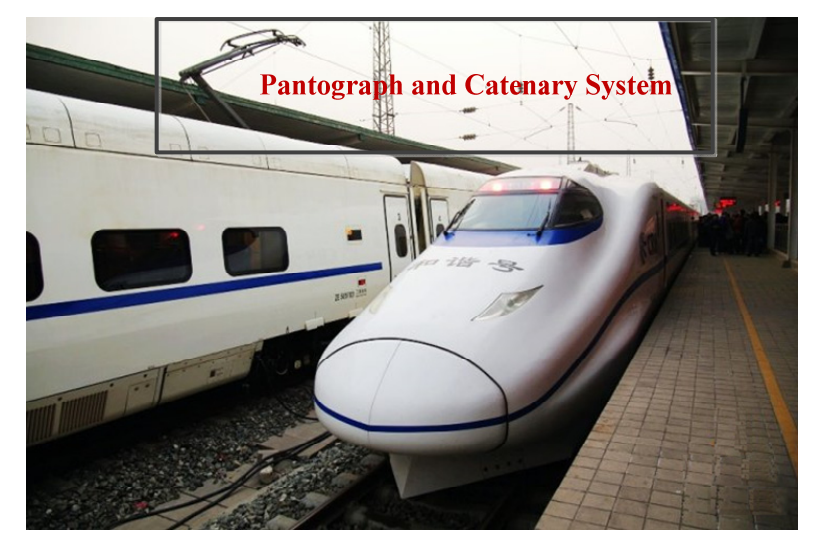

Figure 1: Pantograph and catenary system in a high-speed railway.

There are many researches in simulation of pantograph and catenary system. Benet et al. [1], Teichelmann [2] and Jensen [3] respectively built up motion equations of pantographs and catenary based on its dynamic equation, and proposed calculation model for system's numerical calculation. Ramos [4] and Mei et al. [5] set up models of pantographs and catenary and did simulation in general finite element software such as ANSYS. In the paper [6], catenary was equivalent to a one-dimension stiffness-changing mass-included spring, and based on the model, contact force can be solved with pantograph's dynamic equations. However, catenary is large-span continuous structure that cannot be well presented by the model. Hao [7] simulated dynamics of pantographs and conductor rails which are usually used in urban transit. In addition, literature [8-12] introduced several business simulation software for pantograph and catenary system including GASENDO-FE from Japan, OSCAR from SNCF, CATMOS from BB, SicatMaster for Siemens and PrOSA from DB. Besides these literature showed some examples.

To summarize the simulations discussed above, most researchers took focus on the process of setting up simulation model, but were lack of verifying of their simulation models. To obtain dynamic behaviors and optimize the character of pantograph and catenary system in high-speed railway, the author built up the simulation system by FEM (Finite Element Method), and compared it with standards, commercial software and measured data to verify its reliability. By using the simulation system, contact force between pantograph and catenary and uplift value of contact wire can be calculated when taking different pantographs and catenaries. The results can optimize parameters of catenary structure with specified pantograph types, guide system design and construction and ensure good current collection. 


\section{Evaluation criterion of pantograph and catenary dynamic system}

Pantograph and catenary are contacted by sliding. And the system can stay in two conditions: separate and contact. Usually, when contact force is less than 0 , it is thought that there is an offline happened to pantograph, where electric arc may occur and damage contact wires and pantographs. However, when contact force is too large, physical deterioration which reduces service life of the system may increase because of sliding friction.

Therefore, the key of pantograph and catenary system simulation is to get the contact force and deformation of catenary and pantograph, whose evaluation criterions can refer to EN50119:2006 [13], EN50206:2010 [14] and UIC799:2002 [15]. Details are as follows:

1) Target value of contact force $\left(F_{t}\right): F_{t}=0.00097 \cdot v^{2}+70 \mathrm{~N}$, where $v$ is operation speed of pantograph $(\mathrm{km} / \mathrm{h})$;

2) Maximum standard deviation $\left(\sigma_{\max }\right): \sigma_{\max }<0.3 F_{t}$;

3) Maximum permissible dynamic contact force $\left(F_{m a}\right)$ : $F_{\text {max }}=F_{m}+3 \sigma<350 N($ speed over $230 \mathrm{~km} / \mathrm{h})$;

4) Minimum permissible dynamic contact force $\left(F_{\min }\right)$ : $F_{\text {min }}=F_{m}-3 \sigma>0$;

5) Maximum uplift of locating point $\left(d_{u p}\right): d_{u p} \leq 120 \mathrm{~mm}$;

6) Maximum vertical motion range of pantograph ( $\Delta z): \Delta z \leq 80 \mathrm{~mm}$;

7) Permissible arcing rate $(N Q): N Q \leq 0.2 \%$.

\section{Modelling of pantograph and catenary simulation system}

The pantograph and catenary system is time varying and nonlinear. Nonlinear behaviors include slide contact and friction force of pantograph, hinge of droppers and fixed points and relaxation of droppers. The key of simulation is to build up models for these nonlinear phenomena.

To build up FEM model of catenary, it need to make an assumption that masks and support device are all completely fixed, in other words, no effect from masks and support devices. Only FEM model of position devices and suspension is considered.

The core of catenary is suspension that consists of contact wire, messenger wire, stitch wire, droppers and tension compensation devices etc. in which contact wire, messenger wire and stitch wire are usually treated as Euler-Bernoulli beam elements or cable elements. Beam element involves in bending deflection, whose speed can be present as eqn (1); cable element are not considered bending deflection, whose speed can be present as eqn (2):

$$
\begin{gathered}
C_{B}=\sqrt{\frac{\pi^{2} E I}{m L^{2}}+\frac{N}{m}} \\
C_{S}=\sqrt{\frac{N}{m}}
\end{gathered}
$$


where:
$E I$ - bending strength of the beam (pa);
$m$ - mass per unit length of the beam or cable $(\mathrm{kg} / \mathrm{m})$;
$L$ - length of the beam (m);
$N$ - pretension force of the beam or cable $(\mathrm{N})$.

Considering bending resistance $E I$ of contact wire, messenger wire and stitch wire is very little that $C_{B} \approx C_{S}$, so it is acceptable to use cable element to present contact wire, messenger wire and stitch wire, as shown in fig. 2. Details about mass-stiffness matrix of cable element can be found in literature [16] that every element has 2 nodes, 6 translation Degrees of Freedom (DoF) and can be present as $\left\{\mathrm{u}_{\mathrm{c}}\right\}=\left[\mathrm{u}_{\mathrm{i}}, \mathrm{v}_{\mathrm{i}}, \mathrm{w}_{\mathrm{i}}, \mathrm{u}_{\mathrm{j}}, \mathrm{v}_{\mathrm{j}}, \mathrm{w}_{\mathrm{j}}\right]^{\mathrm{T}}$. Its FEM equation is as follows:

$$
\left[\mathrm{m}_{\mathrm{c}}\right]\left\{\ddot{\mathrm{u}}_{\mathrm{c}}\right\}+\left[\mathrm{k}_{\mathrm{c}}\right]\left\{\mathrm{u}_{\mathrm{c}}\right\}=\left\{\mathrm{f}_{\mathrm{c}}\right\}
$$

Usually locating point has a stagger value and no lift restriction, therefore it is reasonable to take locating point as a beam element whose ends respectively connect to contact wire and, as shown in fig. 3. Two beam elements make a locating point, and their hinge joint limits DoFs. Since there is a hinge joint between beam elements, 3D beam elements are chosen in this model, as shown in fig. 4. Every $3 \mathrm{D}$ beam element whose cell node matrix is $\left\{\mathrm{u}_{\mathrm{s}}\right\}=\left[\mathrm{u}_{\mathrm{i}}, \mathrm{v}_{\mathrm{i}}, \mathrm{w}_{\mathrm{i}}, \theta_{\mathrm{ui}}, \theta_{\mathrm{vi}}, \theta_{\mathrm{wi}}, \mathrm{u}_{\mathrm{j}}, \mathrm{v}_{\mathrm{j}}, \mathrm{w}_{\mathrm{j}}, \theta_{\mathrm{uj}}, \theta_{\mathrm{vj}}, \theta_{\mathrm{wj}}\right]^{\mathrm{T}}$ has 2 nodes, 6 translation DoFs and 6 rotational DoFs. Their mass-stiffness matrix is referred by literature [17], and to single element, the FEM equation is as follows:

$$
\left[\mathrm{m}_{\mathrm{s}}\right]\left\{\ddot{\mathrm{u}}_{\mathrm{s}}\right\}+\left[\mathrm{k}_{\mathrm{s}}\right]\left\{\mathrm{u}_{\mathrm{s}}\right\}=\left\{\mathrm{f}_{\mathrm{s}}\right\}
$$

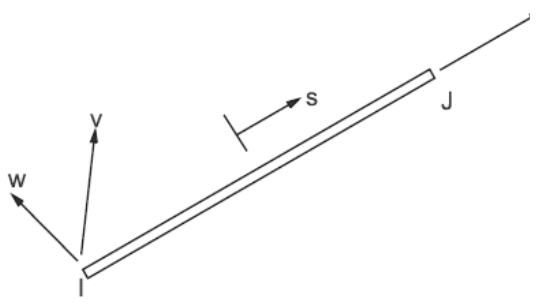

Figure 2: DoFs of a cable element.

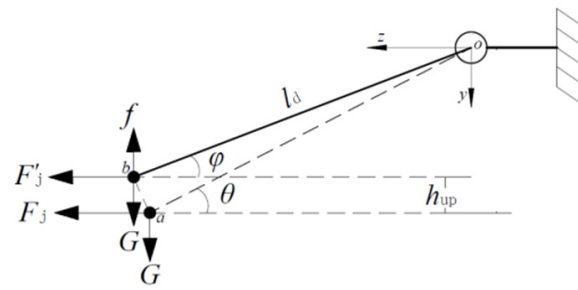

Figure 3: Equivalent model of supporting point. 


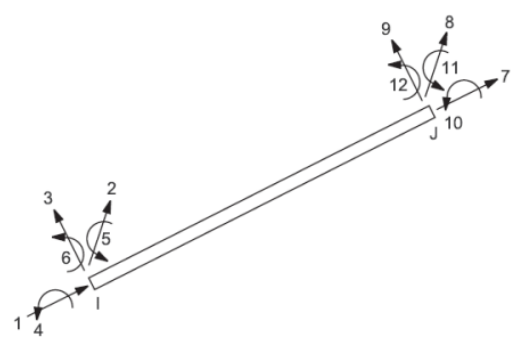

Figure 4: DoFs of a beam element.

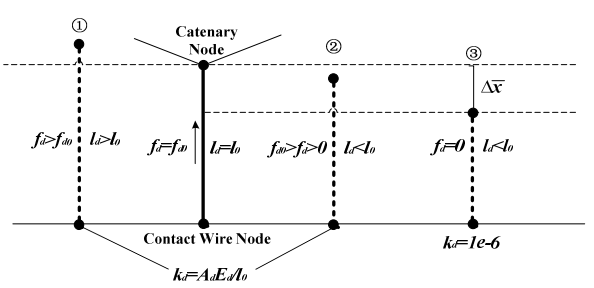

Figure 5: Dropper status.

Because of contact force between pantograph and catenary, there are 2 status of complete-set droppers: strained and unstrained. Therefore, droppers can be presented by stiffness-changing nonlinear cable elements while clips of a drop can be treated as concentrated mass. Kinetic equations of catenary include nonlinear units, so it is necessary to calculate status of droppers in each time step. Criteria of dropper status is as follows:

$$
\left[B_{d}\right]_{t+\Delta t}=\left[k_{d}\right]_{t}\{\Delta \bar{x}\}_{t}-\left\{f_{d}\right\}_{0}
$$

where:

$\left[B_{d}\right]_{t+\Delta t}$ is the judgment matrix for droppers' state at $t+\Delta t$ moment;

$\left[k_{d}\right]$ is droppers' entire stiffness matrix, in which there are non-linear terms;

$\{\Delta \bar{x}\}_{t}$ is displacement difference of dropper's two ends;

$\left\{f_{d}\right\}_{0}$ is initial force of droppers.

To illustrate nonlinear phenomenon of droppers deformation, it assumes that end nodes that connect to contact wire are all at same height, therefore $\{\Delta \bar{x}\}$ is only concerned to displacement of the other end nodes connecting to messenger wire, as shown in fig. 5 . In $\left[k_{d}\right]$, nonlinear terms can be present as $k_{d}=A_{d} E_{d} / l_{d 0}$, where $A_{d} \times E_{d}$ is tensile strength of droppers, $l_{d 0}$ is initial length of droppers. In calculation of $\left[B_{d}\right]_{t+\Delta t}$, if element in $\left[B_{d}\right]_{t+\Delta t}$ is over than 0 , droppers seem to be tensioned at the moment $t+\Delta t$, as (1) and (2) in fig. $5,\left[k_{d}\right]_{t+\Delta t}=A_{d} E_{d} / l_{d 0}$; if else, droppers are in compression as (3in fig. 5, $\left[k_{d}\right]_{t+\Delta t}=1 e-6$. After $\left[k_{d}\right]_{t+\Delta t}$ is got, $[x]_{t+\Delta t}$ can be calculated according to eqn (3).

The nature of complete-set droppers is a cable element, but its stiffness changes with state matrix $\left[B_{d}\right]_{t}$, its FEM equation is as follows:

$$
\left[m_{d}\right]\left\{\ddot{u}_{d}\right\}+\left[k_{d}\right]_{t}\left\{u_{d}\right\}=\left\{f_{d}\right\}
$$

Contact wire, messenger wire, stitch wire, droppers and locating points are taken unified mass elements. 
By coordinate transformation, element's local coordinate system can be converted into a global coordinate system. Considering eqn (3), eqn (4) and eqn (6), the FEM equation of entire catenary can be written as,

$$
\left[M_{c a}\right]\left\{\delta_{c a}^{\ddot{*}}\right\}_{t}+\left[K_{c a}\right]_{t}\left\{\delta_{c a}\right\}_{t}=\left[F_{c a}\right]_{t}
$$

External force matrix $\left[F_{c a}\right]$ presents all external loads, which should be evaluated in every time step. When $t+\Delta t$, it is assumed that

$$
\left[F_{c a}\right]_{t}=[G]+[N]+\left[F_{c}\right]_{t}
$$

in which, $[G]$ and $[N]$ respectively denotes gravity and tension force of catenary, which are constant. Matrix [G] is contact force between pantograph and catenary, and its position changes with time.

Usually pantographs are simplified as concentrated mass models, including 2-mass model, 3-mass model and multi-mass model. Pantograph DSA380 can be equivalent to a 3-mass model as shown in fig. 4 , and its dynamic equation is as eqn (9).

$$
\left[M_{p a}\right]\left\{\ddot{y}_{p a}\right\}_{t}+\left[C_{p a}\right]\left\{\dot{y}_{p a}\right\}_{t}+\left[K_{p a}\right]\left\{y_{p a}\right\}_{t}=\left\{F_{c}\right\}_{t}
$$

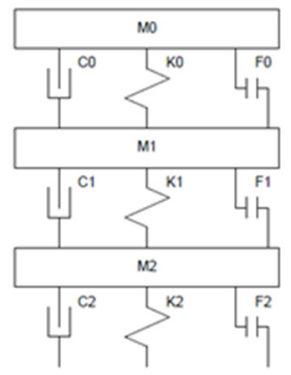

Figure 6: Three mass model of pantographs.

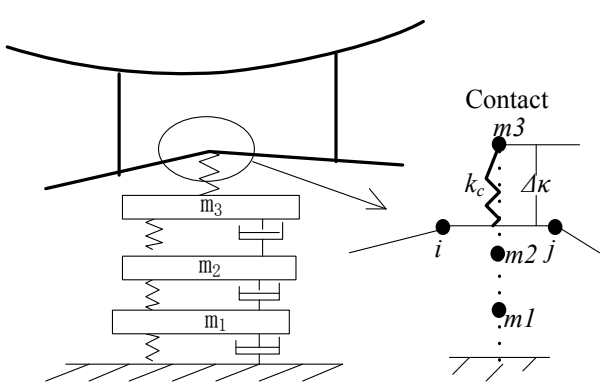

Figure 7: Contact model of pantograph-catenary.

Last but not least, the interaction can be simplified to a slide contact. During sliding, offline occurs. Using Newmark- $\beta$ integration methods, time should be discretized to time step, and the movement of pantograph can be divided into steps that is directly concerned to moving speed.

Generally speaking, penalty function can be used to solve contact problems. It is accepted to set the vertical displacement of contact element $i-j$ and mass point $m_{3}$ as $\Delta \kappa$ and upward is the positive direction. As shown in fig. 7 when the value of $\Delta \kappa$ is positive, it is thought to be permeation state; when $\Delta \kappa$ is negative that to say element $i-j$ is below the mass point $m_{3}$, it is thought to be separation state. 
Contact state is judged by sign symbol of value $\Delta \kappa$, and contact force can be calculated by:

$$
F_{c}(t)=\left\{\begin{array}{cc}
k_{c} \cdot \Delta \kappa(t) & \Delta \kappa(t) \geq 0 \\
0, & \Delta \kappa(t)<0
\end{array}\right.
$$

Therefore, contact force can be calculated according to contact stiffness and $\Delta \kappa$ and used in calculation of next node's displacement in next time step. Repeatedly, the interaction can be calculated.

Combine eqn (7) and eqn (10) to get unified FEM equation of pantograph and catenary,

$$
\begin{array}{r}
{\left[\begin{array}{cc}
{\left[M_{c a}\right]} & 0 \\
0 & {\left[M_{p a}\right]}
\end{array}\right]\left\{\begin{array}{c}
\delta_{c a}^{*} \\
\ddot{y}_{p a}
\end{array}\right\}_{t}+\left[\begin{array}{cc}
0 & 0 \\
0 & {\left[C_{p a}\right]}
\end{array}\right]\left\{\begin{array}{c}
\delta_{c a}^{\cdot} \\
y_{p a}
\end{array}\right\}_{t}+} \\
{\left[\begin{array}{cc}
{\left[K_{c a}\right]_{t}} & 0 \\
0 & {\left[K_{p a}\right]}
\end{array}\right]\left\{\begin{array}{l}
\delta_{c a} \\
y_{p a}
\end{array}\right\}_{t}=[F]_{t}}
\end{array}
$$

Stiffness matrix $\left[K_{c a}\right]$ in eqn (11) can be found in eqn (5), and contact force matrix $[F]_{t}$ can be obtained by eqn (10). Assuming $\{u\}$

$$
\begin{aligned}
& \{\dot{u}\}_{t+\Delta t}=\{\dot{u}\}_{t}+\left((1-\beta)\{\ddot{u}\}_{t}+\beta\{\ddot{u}\}_{t+\Delta t}\right) \Delta t \\
& \{u\}_{t+\Delta t}=\{u\}_{t}+\{\dot{u}\}_{t} \Delta t+\left(\left(\frac{1}{2}-\gamma\right)\{\ddot{u}\}_{t}+\gamma\{\ddot{u}\}_{t+\Delta t}\right) \Delta t^{2}
\end{aligned}
$$

where $\beta=0.5, \gamma=0.25$, average acceleration method is used that from $t$ to $t+\Delta t$, the acceleration is constant at $\frac{1}{2}\left(\{\ddot{u}\}_{t}+\{\ddot{u}\}_{t+\Delta t}\right)$. According to eqn (12) and eqn (13), eqn (11) can be integrated.

At the moment $t,\{\mathrm{u}\}$ and $\{\dot{u}\}$ can be got by eqn (13) and eqn (12). Taking $\{u\}_{t},\{\dot{u}\}_{t}$ and $\left[K_{c a}\right]_{t}$ into eqn (11), $\{\ddot{u}\}$ at $t+\Delta t$ can be solved, then $\{\mathrm{u}\}$ and $\{\dot{u}\}$ can be re-calculated by using eqn (12) and eqn (13). The process of calculation can be found in fig. 8 .

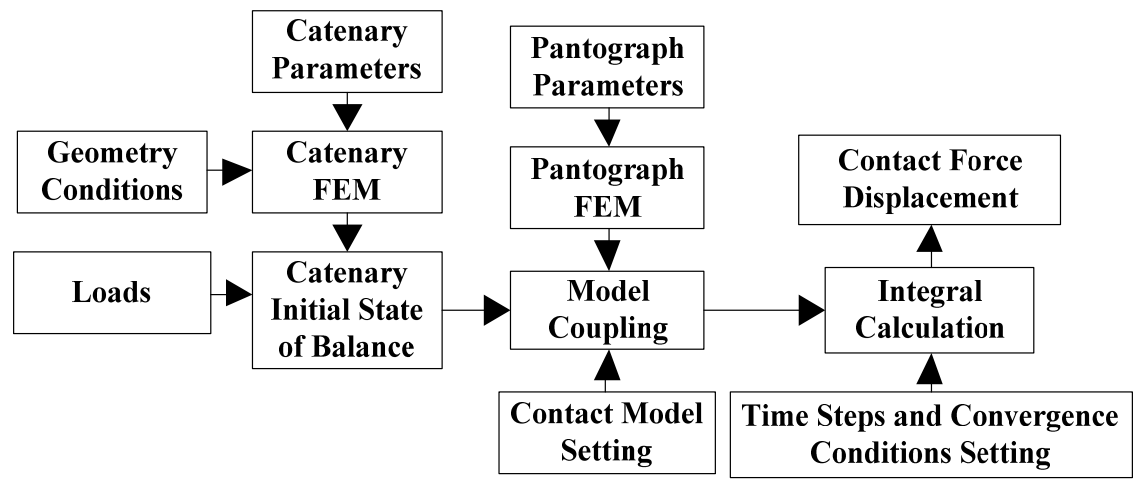

Figure 8: Finite element calculation process of pantograph-catenary. 


\section{Verification of simulation system}

\subsection{Comparison to relative standards}

Standard EN50318 [18] gives a detailed description of the verification of the dynamic simulation system of pantograph and catenary. It expressly stipulates that simulation system should be convinced by both the case in EN50318 and measured data. In that case, catenary example is a 10-span $60 \mathrm{~m}$ length simple chain suspension, while pantograph is defined as a discrete mass-spring-damper model. According to parameters given in Annex A of EN50318, the model of pantograph and catenary is built up in simulation system, as shown in fig. 9. The simulation was proceeding in accordance with Chapter 2. The results in $250 \mathrm{~km} / \mathrm{h}$ and $300 \mathrm{~km} / \mathrm{h}$ are shown in Table 1 .

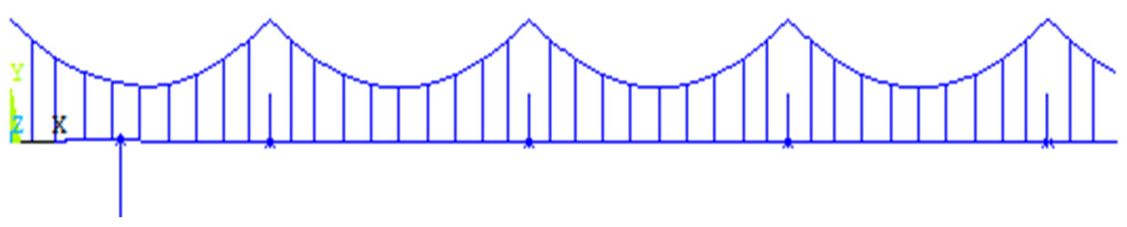

Figure 9: Simulation model of pantograph and catenary system in EN50318.

Table 1: Dynamic interaction parameters of pantograph and catenary.

\begin{tabular}{|c|c|c|c|c|}
\hline \multirow{2}{*}{\begin{tabular}{c} 
Parameters \\
\cline { 2 - 5 }
\end{tabular}} & \multicolumn{3}{|c|}{$\begin{array}{c}\text { Validation range in } \\
\text { EN50318 }\end{array}$} & \multicolumn{2}{c|}{ Simulation result } \\
\cline { 2 - 5 }$\left(5^{\text {th }}\right.$ and $6^{\text {th }}$ span, low pass filtering $\left.20 \mathrm{~Hz}\right)$ \\
\hline Speed (km/h) & 250 & 300 & 250 & 300 \\
\hline $\begin{array}{c}\text { Mean value of the contact force } \\
(\mathrm{N})\end{array}$ & $110-120$ & $110-120$ & 116.7 & 116.1 \\
\hline $\begin{array}{c}\text { Standard deviation of the contact } \\
\text { force }(\mathrm{N})\end{array}$ & $26-31$ & $32-40$ & 28.2 & 33.5 \\
\hline $\begin{array}{c}\text { Statistical maximum of contact } \\
\text { force }(\mathrm{N})\end{array}$ & $190-210$ & $210-230$ & 201.3 & 216.6 \\
\hline $\begin{array}{c}\text { Statistical minimum of contact } \\
\text { force (N) }\end{array}$ & $20-40$ & $-5-20$ & 32.1 & 15.6 \\
\hline $\begin{array}{c}\text { Actual maximum of contact force } \\
(\mathrm{N})\end{array}$ & $175-210$ & $190-225$ & 180.3 & 207.4 \\
\hline $\begin{array}{c}\text { Actual minimum of contact force } \\
(\mathrm{N})\end{array}$ & $50-75$ & $30-55$ & 58.2 & 42.6 \\
\hline Uplift value at locating point (mm) & $48-55$ & $55-65$ & 52.5 & 56.8 \\
\hline Percentage of loss of contact (\%) & 0 & 0 & 0 & 0 \\
\hline
\end{tabular}

TH simulation results are all in validation range given in EN50318, therefore the simulation system is thought to pass the validation. 


\subsection{Comparison to commercial software}

Wu-Guang high-speed railway is designed by Balour Beatty (BB), Germany. Pantograph and catenary simulation software CATMOS was applied to this program. In this section, simulation results were taken in comparison with ones from CATMOS to make the simulation system convincible. Table 2 shows catenary design parameters of Wu-Guang high-speed railway and Table 3 shows parameters of DSA380 that is used in Wuhan-Guangzhou high-speed railway. Contact stiffness $k_{c}$ is $50000 \mathrm{~N} / \mathrm{m}$ defined in EN50318. 20-span simulation model is built up and shown in fig. 10 where spans from $7^{\text {th }}$ to $13^{\text {th }}$ are used as analysis section. The contact force calculated by CATMOS is shown in fig. 11 while result from simulation system that is designed by the author was present in fig. 12. The statistical data is shown in Table 4.

Table 2: Catenary design parameters of $\mathrm{Wu}-\mathrm{Guang}$ high-speed railway.

\begin{tabular}{|l|l|l|l|}
\hline Parameters & Property & Parameters & Property \\
\hline $\begin{array}{l}\text { Weight per unit length of } \\
\text { contact wire }\end{array}$ & $\begin{array}{l}1.035^{*} 9.8 \\
\mathrm{~N} / \mathrm{m}\end{array}$ & $\begin{array}{l}\text { weight per unit length of } \\
\text { messenger wire }\end{array}$ & $\begin{array}{l}1.065^{*} 9.8 \\
\mathrm{~N} / \mathrm{m}\end{array}$ \\
\hline Tension force of contact wire & $30 \mathrm{kN}$ & $\begin{array}{l}\text { Tension force of contact } \\
\text { wire }\end{array}$ & $21 \mathrm{kN}$ \\
\hline Material of stitched wire & $\mathrm{JTMH} 35$ & Material of droppers & $\mathrm{JTxMH10}$ \\
\hline $\begin{array}{l}\text { Weight per unit length of } \\
\text { stitched wire }\end{array}$ & $\begin{array}{l}0.311^{*} 9.8 \\
\mathrm{~N} / \mathrm{m}\end{array}$ & $\begin{array}{l}\text { weight per unit length of } \\
\text { dropper wire }\end{array}$ & $\begin{array}{l}0.09 * 9.8 \\
\mathrm{~N} / \mathrm{m}\end{array}$ \\
\hline Length of stitched wire & $14-18 \mathrm{~m}$ & Weight of dropper clamp & $0.15 \mathrm{~kg}$ \\
\hline Tension force of stitched wire & $3.5 \mathrm{kN}$ & Standard span length & $48 \mathrm{~m}$ \\
\hline Structure height & $1.6 \mathrm{~m}$ & Stagger value & $250 \mathrm{~mm}$ \\
\hline $\begin{array}{l}\text { Distance between locating } \\
\text { point to } 1^{\text {st }} \text { dropper }\end{array}$ & $5 \mathrm{~m}$ & $\begin{array}{l}\text { Spacing between adjacent } \\
\text { droppers }\end{array}$ & Max. $10 \mathrm{~m}$ \\
\hline $\begin{array}{l}\text { Weight per unit length of } \\
\text { locator }\end{array}$ & $1.44^{*} 9.8$ & Length of locator & $1.25 \mathrm{~m}$ \\
\hline
\end{tabular}

Table 3: Parameters of DSA 380 pantographs.

\begin{tabular}{|c|c|c|c|c|c|}
\hline $\begin{array}{l}\text { Equivalent } \\
\text { parameters }\end{array}$ & Symbol & Value & Equivalent parameters & Symbol & Value \\
\hline \multirow{3}{*}{ Mass (kg) } & M0 & 7.12 & \multirow{3}{*}{ Damping (Ns/m) } & $\mathrm{C} 0$ & 0 \\
\hline & M1 & 6 & & $\mathrm{C} 1$ & 0 \\
\hline & M2 & 5.8 & & $\mathrm{C} 2$ & 70 \\
\hline \multirow{3}{*}{ Stiffness (N/m) } & K0 & 9430 & \multirow{3}{*}{ Frictional force $(\mathrm{N})$} & F0 & 0.5 \\
\hline & $\mathrm{K} 1$ & 14100 & & F1 & 3.5 \\
\hline & K2 & 0.1 & & $\mathrm{~F} 2$ & 3.5 \\
\hline
\end{tabular}




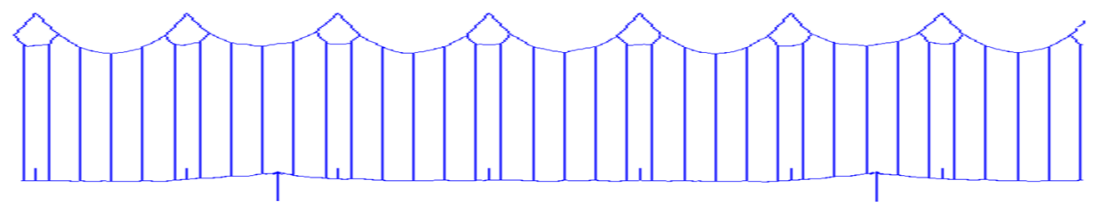

Figure 10: Dynamic simulation model of pantograph and catenary system in Wu-Guang highspeed railway.

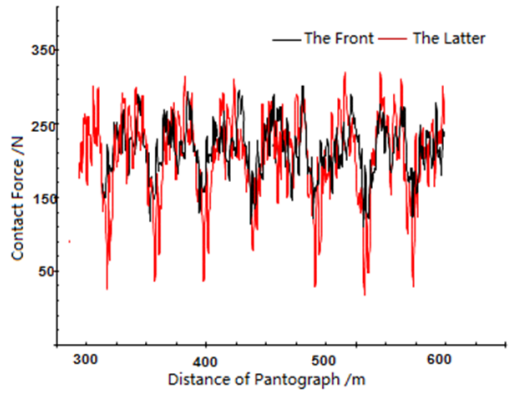

Figure 11: Simulation result from CATMOS.

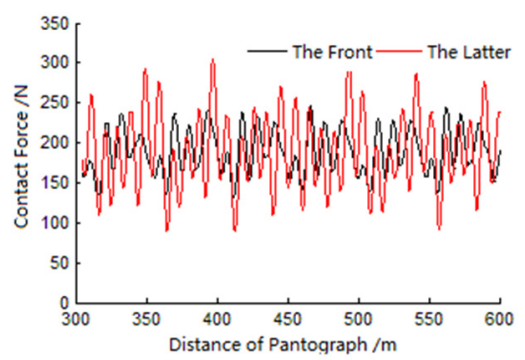

Figure 12: Simulation result from designed system.

Table 4: Simulation result comparison between CATMOS and designed simulation system.

\begin{tabular}{|l|c|c|c|c|}
\hline \multicolumn{1}{|c|}{$\begin{array}{c}\text { Analysis section (7th and } \\
13^{\text {th }} \text { span, low pass filtering }\end{array}$ 20 Hz) } & \multicolumn{2}{|c|}{ Result from CATMOS } & \multicolumn{2}{c|}{ Result from designed system } \\
\cline { 2 - 5 } & $\begin{array}{c}\text { Front } \\
\text { pantograph }\end{array}$ & $\begin{array}{c}\text { Rear } \\
\text { pantograph }\end{array}$ & $\begin{array}{c}\text { Front } \\
\text { pantograph }\end{array}$ & $\begin{array}{c}\text { Rear } \\
\text { pantograph }\end{array}$ \\
\hline $\begin{array}{l}\text { Mean value of the contact } \\
\text { force (N) }\end{array}$ & 186.9 & 187 & 188.9 & 189.6 \\
\hline $\begin{array}{l}\text { Standard deviation of the } \\
\text { contact force (N) }\end{array}$ & 32.7 & 40.5 & 26.9 & 45.9 \\
\hline $\begin{array}{l}\text { Statistical maximum of } \\
\text { contact force (N) }\end{array}$ & 88.8 & 65.5 & 108.2 & 51.9 \\
\hline $\begin{array}{l}\text { Statistical minimum of } \\
\text { contact force (N) }\end{array}$ & 285 & 308.5 & 269.6 & 327.3 \\
\hline $\begin{array}{l}\text { Actual maximum of } \\
\text { contact force (N) }\end{array}$ & 265.1 & 318.9 & 246.4 & 307.8 \\
\hline $\begin{array}{l}\text { Actual minimum of contact } \\
\text { force (N) }\end{array}$ & 64.4 & 43.5 & 132.8 & 89.4 \\
\hline $\begin{array}{l}\text { Uplift value at locating } \\
\text { point (mm) }\end{array}$ & 28 & 46 & 74.89 & 71.12 \\
\hline
\end{tabular}


According to EN50318 clause 10.1, standard deviation of contact force from different simulation systems should be within the error range, $\pm 20 \%$, so as uplift of locating points. As seen in Table 4, contact force error of former pantograph from both simulation systems is $-17.7 \%$ while the number of latter one is $13.3 \%$. Obviously simulation results of contact force meet the criterion. However, uplift error of locating point is unexpectedly large, so it is need to valid the uplift value of locating point by measured data.

\subsection{Comparison to measured data}

To verify the credibility of simulation model, catenary vibration condition of Wu-Guang high-speed railway has been field tested. Bei-Xiang Bridge (DK1934+010) was selected to be measure point. High-speed industrial camera, as shown in fig. 13, was used to catch pictures, where moving trajectory of supporting point can be recognized. Displacements of supporting point at $339.5 \mathrm{~km} / \mathrm{h}$ and $345.7 \mathrm{~km} / \mathrm{h}$ are shown in fig. 14, where $\mathrm{x}$ axis directs time and $\mathrm{y}$ axis presents uplift. Fig. 15 shows the simulation results of supporting point on particularly anchor mast. Comparing fig. 14 and fig. 15, it can be seen that their trends are basically identical and detailed comparison can be found in Table 5. As shown in Table 5, maximum simulation displacements of both pantographs are closed to the measured ones, with no more than $20 \%$ error, which make the simulation system convinced.

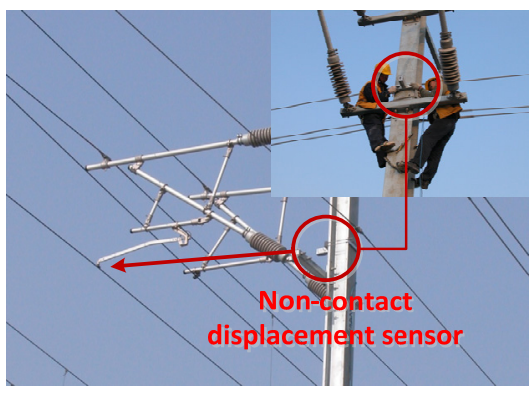

Figure 13: Measurement at supporting point.

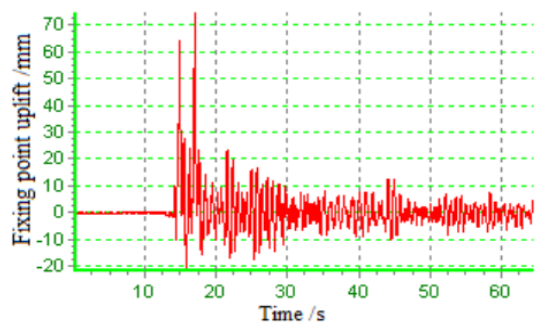

(1) $339.5 \mathrm{~km} / \mathrm{h}$

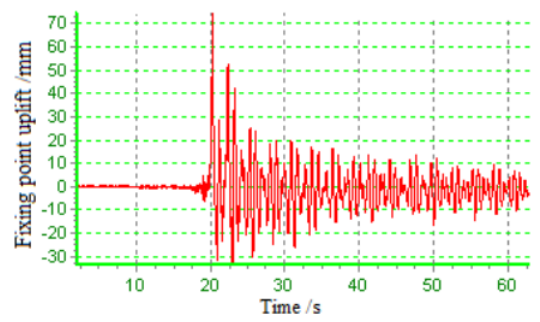

(2) $345.7 \mathrm{~km} / \mathrm{h}$

Figure 14: Measurement results at supporting point. 


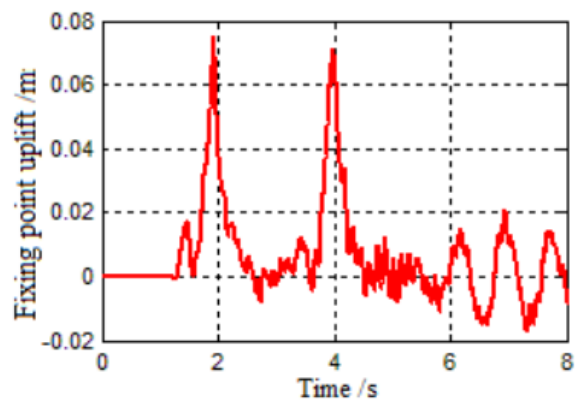

Figure 15: Simulation results at supporting point.

Table 5: Displacement of supporting point by measuring and simulating.

\begin{tabular}{|c|c|c|c|c|}
\hline \multirow{2}{*}{ Speed $(\mathrm{km} / \mathrm{h})$} & \multicolumn{2}{|c|}{$\begin{array}{c}\text { Maximum uplift value at } \\
\text { locating point }(\mathrm{mm})\end{array}$} & $\begin{array}{c}\text { Difference between measured value } \\
\text { and simulation value }\end{array}$ \\
\cline { 2 - 5 } & $\begin{array}{c}\text { Front } \\
\text { pantograph }\end{array}$ & $\begin{array}{c}\text { Rear } \\
\text { pantograph }\end{array}$ & $\begin{array}{c}\text { Front } \\
\text { pantograph }\end{array}$ & Rear pantograph \\
\hline 339.5 (measure) & 64.243 & 74.447 & $16.6 \%$ & $-4.5 \%$ \\
\hline 345.7 (measure) & 75.177 & 52.202 & $-0.4 \%$ & $36.2 \%$ \\
\hline 350 (simulate) & 74.89 & 71.12 & & \\
\hline
\end{tabular}

\section{Conclusion}

The author designed a simulation system for pantograph and catenary dynamic system by using FEM method and dealing nonlinear behaviors by penalty function. By using the simulation system, main dynamic parameters of pantograph and catenary system such as contact force and displacement of pantographs and catenary can be got on basis of structure parameters of pantograph and catenary. According to relative standard, results of simulation model basically meet the standard requirements. Additionally, simulation system is compared to CATMOS that was applied in design of Wuhan-Guangzhou high-speed railway, and the results shows errors between both systems are less that $20 \%$. Finally, the simulation system is verified by measured data in Wuhan-Guangzhou high-speed railway. Comparing to standards, commercial software and measured data, the credibility of the simulation system is thought to be valid and convinced.

\section{References}

[1] Benet, J., Alberto, A., Arias, E., \& Rojo, T., A Mathematical Model of the Pantograph-Catenary Dynamic Interaction with Several Contact Wires. International Journal of Applied Mathematics, 37(2), 2007.

[2] Teichelmann, G., Modelling and simulation of railway cable systems. ZAMM - Journal of Applied Mathematics and Mechanics/Zeitschrift für Angewandte Mathematik und Mechanik, 85(12), pp. 864-877, 2005. 
[3] Jensen, C. N., Dynamics of an Electrical Overhead Line System and Moving Pantographs. Vehicle System Dynamics Supplement. 29(S1), pp. 104-113, 1998.

[4] Ramos, A., Dynamic simulation of the system pantograph-catenaryvehicle-track. Proc. of the $9^{\text {th }}$ World Congress on Railway Research, UIC, 2011.

[5] Mei, G., Zhang, W., Zhao, H., \& Zhang, L., A hybrid method to simulate the interaction of pantograph and catenary on overlap span. Vehicle System Dynamics, 44(sup1), pp. 571-580, 2006.

[6] Qu, Y., Modelling and simulation analyse of pantograph and catenary system in electric railway (in Chinese). Computer simulation, 30(6), pp. 202-360, 2013.

[7] Hao, X., Modelling and simulation of pantograph and catenary system in urban rail transit (in Chinese). Computer simulation, 30(10), pp. 194-198, 2013.

[8] RTRI, Characteristic of pantograph and catenary (in Chinese). China CREC railway electrification bureau group, trans. Beijing: China railway publishing house, 2010.

[9] Bobillot, A., Pantograph-Catenary: a High-Speed European couple. Proc. of the $8^{\text {th }}$ World Congress on Railway Research, UIC, 2010.

[10] Li, J., Overhead Line Simulation Research for Wire Tensile Forces Optimization. Proc. of the $1^{\text {st }}$ International Workshop on High-speed and Intercity Railways, Springer Berlin Heidelberg, pp. 309-317, 2012.

[11] Kiessling, F, Puschmann, R. Schmieder, A. \& Schneider, E., Contact lines for electric railways planning, design, implementation, maintenance, Publicis Corporate Publishing, Erlangen, pp. 639-656, 2009.

[12] Thorsten, S., Simulating the dynamic interaction between pantograph and catenary. Proc. of the $1^{1^{s t}}$ World Congress on Railway Research, UIC, 2001.

[13] EN50119:2006 Railway applications - Fixed installations - Electric traction overhead contact lines. Brussels: CENELLEC, 2006.

[14] EN50206:2010 Railway applications - Rolling stock - Pantographs: Characteristics and tests. Brussels: CENELLEC, 2010.

[15] UIC799:2002 characteristics of A.C. overhead contact systems for highspeed lines worked at speeds of over $200 \mathrm{~km} / \mathrm{h}$. UIC Codex, 2002.

[16] Yunus, S. M., Pawlak, T. P., \& Cook, R. D., Solid element with rotational degrees of freedom part 1 and part 2. International Journal for Numerical Methods in Engineering. 31(3), pp. 573-610, 1991.

[17] Przemieniecki, J. S., Theory of Matrix structural analysis. McGraw-Hill. New York, 1968.

[18] EN50318:2002. Railway applications - Current collection system Validation of simulation of the dynamic interaction between pantograph and overhead contact line. Brussels: CENELLEC, 2002. 